$$
\text { CONF-970677--12 }
$$

For Presentation at the Air \& Waste Management Association's 90th Annual Meeting \& Exhibition, June 8-13, 1997, Toronto, Ontario, Canada

97-WP72B.01

ANL/ES/CP_- 91309

\title{
Enhanced Control of Mercury Emissions Through Modified Speciation
}

\section{David Livengood and Marshall H. Mendelsohn}

Argonne National Laboratory, 9700 S. Cass Avenue, Argonne, IL 60439

\section{Introduction}

The control of hazardous air pollutant (HAP) emissions was addressed in Title III of the Clean Air Act Amendments of 1990, which provided an initial list of 189 elements and compounds of concern. The combustion of coal has the potential to produce a number of those species, either directly as a result of the trace elements found in coal, or as products of chemical reactions occurring in combustion.

However, field studies conducted by the U.S. Department of Energy (DOE), the Electric Power Research Institute (EPRD), and others have shown that the actual emissions are very low and that effective particulate-matter capture can control most of the inorganic species. The most significant exception is mercury, which has also been singled out for particular regulatory attention because of its behavior in the environment (bioaccumulation) and the potential for deleterious health effects.

In anticipation of possible regulations regarding mercury emissions, research efforts sponsored by DOE, EPRI, and others are investigating the risks posed by mercury emissions, improved techniques for measuring those emissions, and possible control measures. The focus in the control research is on techniques that can be used in conjunction with existing flue-gas-cleanup (FGC) systems in order to minimize additional capital costs and operational complexity. The very small amount of mercury (on the order of a few micrograms per cubic meter) in flue gas, its occurrence in several chemical forms that vary from system to system, the very low solubility of the elemental form, and the fact that it is usually in the vapor phase combine to make the achievement of cost-effective control a challenging task.

Argonne National Laboratory has supported the DOE Fossil Energy Program for over 15 years with research on advanced environmental control technologies. The emphasis in Argonne's work has been on integrated systems that combine control of several pollutants. Specific topics have included spray drying for sulfur dioxide and particulate-matter control with high-sulfur coal, combined sulfur dioxide and nitrogen oxides control technologies, and techniques to enhance mercury control in existing FGC systems. The latter area has focused on low-cost dry sorbents ${ }^{1}$ for use with fabric filters or electrostatic precipitators and techniques for improving the capture of mercury in wet flue-gas desulfurization (FGD) systems. One way of improving that capture is to convert relatively insoluble elemental mercury $\left(\mathrm{Hg}^{0}\right)$ to a more soluble form, such as mercuric chloride (see Table 1 for a list of selected chemical formulas). This paper presents results from recent work that has studied the effects of several oxidizing agents in combination with typical flue-gas species (e.g., nitrogen oxides and sulfur dioxide) on the oxidation of $\mathrm{Hg}^{0}$. The results of initial laboratory studies indicate that conversion of $\mathrm{Hg}^{0}$ to an oxidized form is feasible, and that a combined sulfur dioxide/nitrogen oxides/mercury scrubbing process may be possible.

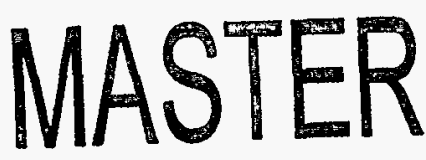

DISTRIBUTION OF THIS DOCUMENT IS UNLIMITID 


\section{DISCLAMIER}

Portions of this doevrment may be illegible in electronic image products. Images are produced from the best available original doccoment. 
Further process development research is designed to determine both the technical and economic potential of such a process.

\section{Background}

The fate of trace elements liberated in the combustion process can be influenced by the type of boiler, the operating conditions, other species present in the flue gas, and the FGC system. Mercury is a particular problem because it belongs to a group of elements and compounds denoted as Class III, which remains primarily in the vapor phase within the boiler and subsequent FGC system. Wet scrubbing is commonly used to control gas-phase species, but in field tests conducted by DOE and EPRI, mercury removal in wet FGD systems has been highly variable. Removal values have ranged from about $10 \%$ to over $80 \%{ }^{2}$ Much of this variation may be caused by differences in the chemical form of the mercury. The presence of chlorine in coal means that mercury can be found in both the elemental and oxidized forms, with the relative amounts depending on such factors as the ratio of chlorine to mercury, the gas temperature, and the gas residence time at various temperatures. ${ }^{3}$ While other species are also possible and may be present in small amounts, these two appear to be the most significant for control considerations. The huge difference in solubility between the two species is particularly important in wet scrubbing applications.

Argonne's research has focused on the control of elemental mercury. Initial experiments ${ }^{4}$ used a laboratory-scale wet scrubbing system that had been well characterized in previous work on combined sulfur dioxide/nitrogen oxides control. ${ }^{5}$ For those tests, the feed-gas stream consisted of nitrogen with about $40 \mu \mathrm{g} / \mathrm{m}^{3}$ of $\mathrm{Hg}^{\circ}$. The scrubber was first operated as a partially flooded column with water, a calcium hydroxide solution, or a calcium hydroxide solution plus potassium polysulfide as the scrubbing liquor. No appreciable mercury removal was found in any of those cases.

Some improvement was found when ceramic-saddle packing was added to the scrubber, but the removals were still under $10 \%$. More promising results were found when the packing was changed to stainless steel and used in conjunction with potassium polysulfide in the scrubbing liquor. Removals of up to $40 \%$ were obtained. However, the use of the polysulfide in FGD systems could be precluded by the fact that a very high $\mathrm{pH}$ is required to maintain its stability.

At that point in the program, the emphasis was shifted to the study of techniques for changing the chemical form of mercury in order to produce a more soluble species. Tests were conducted with several additives that combine strong oxidizing properties with relatively high vapor pressures (e.g., chlorine). Tests with minimal gas-liquid contacting yielded mercury removals as high as $100 \%$ and indicated that the removal reactions were occurring in the gas phase above the scrubber liquor. However, tests with the addition of sulfur dioxide to the gas stream showed the additives to be very reactive with that species as well, which could result in excessively high additive consumption in order to realize effective mercury control.

Next, tests were conducted with a chloric-acid-based chemical, NOXSORB ${ }^{\mathrm{TM}}$, which is a product of the Olin Corporation. Typical feed-gas compositions included $1,000 \mathrm{ppm}$ sulfur dioxide, $200 \mathrm{ppm}$ nitric oxide, $15 \%$ carbon dioxide, and $33 \mu \mathrm{g} / \mathrm{m}^{3}$ of $\mathrm{Hg}^{0}$. Figure 1 shows removal data from a batch test with a dilute (4\%) solution of the as-received NOXSORB ${ }^{\mathrm{TM}}$ concentrate. An outlet reading of zero was obtained for $\mathrm{Hg}^{\circ}$ for approximately $24 \mathrm{~min}$. During that period, the nitric oxide outlet concentration decreased rapidly to near zero and then rose gradually to where it was almost equal to the inlet value. 
The breakthrough in the outlet $\mathrm{Hg}^{0}$ concentration (the point at which the concentration rose above zero) appeared to coincide with the point at which the nitric-oxide concentration leveled off. The apparent correlation between the two removals appeared to imply that the mercury was reacting with a product or intermediate of the nitric-oxide removal process. A moderate degree of sulfur-dioxide removal was also observed during the time the NOXSORB ${ }^{\mathrm{TM}}$ solution was circulating.

The results of that test and others indicated that not only could effective mercury removal be achieved via this approach, but that a combined process that also removed nitric oxide might be feasible. To explore in more detail the interactions among $\mathrm{Hg}^{0}$, oxidizing additives, and the various flue-gas species, a series of experiments using bubblers was designed. The following sections of this paper describe the experimental setup, procedures, and results of those tests.

\section{Experimental Setup and Procedures}

For these experiments, a simulated flue gas was passed through a series of three bubblers for $30 \mathrm{~min}$. A solution of the reactive chemical to be tested was placed in the first bubbler and the degree of $\mathrm{Hg}^{\mathrm{O}}$ conversion was determined by comparing the amount of mercury found in the bubbler solutions with the total amount of $\mathrm{Hg}^{\circ}$ fed in the flue gas. The $\mathrm{Hg}^{0}$ concentration in the gas was typically $45 \mu \mathrm{g} / \mathrm{m}^{3}$.

The source of $\mathrm{Hg}^{0}$ was a calibrated and certified permeation tube from VICI Metronics, which was placed in a constant-temperature water bath controlled to $\pm 0.5^{\circ} \mathrm{C}$. Bottled, high-purity $(99.998 \%)$ nitrogen gas flowed around the permeation tube to produce a gas stream with a constant concentration of $\mathrm{Hg}^{\circ}$. This stream was then combined with another gas stream containing nitrogen and other gaseous components, such as oxygen, carbon dioxide, nitric oxide, and sulfur dioxide. Carbon dioxide was used as a carrier gas for the nitric oxide. Oxygen was obtained from a laboratory air line without further purification. Carbon dioxide, nitric oxide, and sulfur dioxide were used from bottled gases without further purification. The nominal purities for these gases were as follows: carbon dioxide, $99.5 \%$; nitric oxide, $>99.0 \%$; and sulfur dioxide, $>99.98 \%$. After blending, the initial gas composition was checked by using standard flue-gas analyzers from Beckman instruments: oxygen, Model 755 Oxygen Analyzer;


dioxide, Model 865 Infrared Analyzer. Typical concentrations of the various gas components were as follows: oxygen, $5 \%$; carbon dioxide, $15 \%$; nitric oxide, $250 \mathrm{ppm}$; and sulfur dioxide, 1,000 ppm.

After the feed-gas composition was measured and stabilized, a valve was turned to admit the gas mixture to the series of three bubblers, each containing $150 \mathrm{~mL}$ of solution. While the first bubbler contained the solution to be studied, the second and third bubblers usually contained distilled water. Commercial solutions of iodine, bromine, chlorine (sold as sodium hypochlorite), and chloric acid (NOXSORB ${ }^{\mathrm{TM}}$ ) were used without further purification. Following the 30-min test, liquid samples from each bubbler were saved for total mercury analysis. Analyses were performed by a standard cold-vapor atomic absorption spectrophotometric method (U.S. EPA Method 7470A, SW-846). Mercury concentrations were measured to $\pm 0.01 \mu \mathrm{g} / \mathrm{L}$. The estimated accuracy for this method is $\pm 10 \%$.

One objective of the bubbler experiments was to determine the degree to which the important reactions were occurring in the gas phase, the liquid phase, or both. However, this was difficult to determine from the initial arrangement. We could presume that mercury found in the second bubbler was due to gasphase reactions, assuming that liquid carryover from the first bubbler was negligible. However, the 
situation in bubbler \#1 was more complex. We could not distinguish between gas-phase reactions occurring inside the gas bubbles followed by rapid dissolution of products into the liquid phase versus gas-phase dissolution at the gas-liquid interface followed by a rapid liquid-phase reaction. To gain some insights into this issue, a second series of tests was performed, wherein the open-end inlet tube on bubbler \#1 was replaced with a fritted-glass cylinder having a coarse porosity. This gas diffuser greatly decreased the size of the bubbles (by about an order of magnitude) passing through the liquid in the first bubbler, thereby increasing the degree of gas-liquid contact. Thus, we can assume that the results of the small-bubble tests were significantly more influenced by gas-liquid interactions than the corresponding large-bubble tests.

\section{Experiment Results and Discussion}

Before any tests were performed with various solutions in bubbler \#1, a number of baseline tests were carried out with only distilled water in all three bubblers. When no $\mathrm{Hg}^{\circ}$ was added to the gas stream, no mercury was found in any of the bubbler solutions. This result demonstrated that the system was free of mercury contamination to the detection limit $( \pm 0.02 \mu \mathrm{g} / \mathrm{L}$ or $\pm 0.003 \mu \mathrm{g}$ mercury in $150 \mathrm{~mL}$ of water) of the analytical method. Such baseline tests were run periodically to ensure that no mercury contamination had built up during testing. Two tests were performed with $\mathrm{Hg}^{\circ}$ added to the feed-gas stream, but again with only distilled water in all three bubblers. For one test with large bubbles, amounts of mercury barely above the detection limit $(0.004-0.005 \mu \mathrm{g}$ in $150 \mathrm{~mL})$ were found in each of the three bubblers. This amount may be compared with the calculated amount of $\mathrm{Hg}^{0}$ in the gas stream of $1.9 \mu \mathrm{g}$ for the 30 -min test. This result showed that the amount of $\mathrm{Hg}^{\circ}$ removed using only distilled water was less than $0.3 \%$. For a similar test with small bubbles, no mercury was found in either bubbler \#1 or bubbler \#2. Therefore, any amount of mercury found in the bubblers above these baseline amounts must be from reactions of $\mathrm{Hg}^{\circ}$ with components of the various solutions tested in bubbler \#1.

To verify that the effects of other flue-gas components were due to interactions with the test solutions, experiments were run in which the bubblers contained only water. The synthetic flue gas contained either nitrogen, oxygen, sulfur dioxide, and $\mathrm{Hg}^{\circ}$, or nitrogen, oxygen, sulfur dioxide, carbon dioxide, nitric oxide, and $\mathrm{Hg}^{\circ}$. In both cases, less than $1 \%$ of the inlet mercury was found in the liquid phase at the end of the experiment. Thus, the flue-gas species alone are not capable of affecting the solubility of mercury.

The following sections discuss the results of experiments with several different reactive agents in the bubbler \#1 solution. The discussion is divided into two sections, with the results for the large-bubble, open-ended tube presented first, followed by the results for the small bubble, coarse-fritted-cylinder inlet.

\section{Large Bubble Tests}

\section{Iodine Solutions}

A commercial preparation of $0.100 \mathrm{~N}$ iodine solution was diluted to make up various iodine concentrations. Note that commercial iodine solutions generally contain potassium iodide as a stabilizer, as well as dissolved iodine. Previous experiments in our laboratory had shown that iodine solutions react rapidly with mercury vapor in gas streams containing only $\mathrm{Hg}^{\circ}$ and nitrogen. ${ }^{6}$ However, those tests were performed with only a gas-phase $\mathrm{Hg}^{0}$ analyzer to measure the mercury concentration in both the feed and effluent gas streams. We recently showed that the analyzer is unreliable for measuring $\mathrm{Hg}^{0}$ in various 
complex gas mixtures. The tests reported here are the first ones in which liquid-phase mercury has been analyzed.

Using a solution of about $125 \mathrm{ppb}$ iodine in bubbler \#1, we found that more than $90 \%$ of the inlet mercury was retained in the bubbler solutions when only nitrogen and $\mathrm{Hg}^{\circ}$ were in the feed-gas stream. When oxygen and carbon dioxide were added to the gas mixture, $\mathrm{Hg}^{0}$ removal was reduced to about $6 \%$. Only one test was performed with a higher iodine concentration in bubbler \#1 ( $250 \mathrm{ppb}$ iodine). This test, again conducted with a gas stream containing only $\mathrm{Hg}^{0}$ and nitrogen, did not give a result substantially different from the lower concentration test $\left(-81 \% \mathrm{Hg}^{0}\right.$ removal). However, when either nitric oxide or sulfur dioxide (or both) were added to the gas mixture, the amount of mercury found in the bubbler solutions went either to zero (for nitric oxide or for nitric oxide plus sulfur dioxide) or close to zero ( $1 \%$ for sulfur dioxide).

In earlier unpublished work in our laboratory, we found that the concentration of gaseous $\mathrm{Hg}^{\circ}$ was substantially reduced simply by passing $\mathrm{Hg}^{0}$ vapors (mixed with nitrogen gas only) over an agitated iodine solution $(-250 \mathrm{ppb})$. These tests showed that the most likely $\mathrm{Hg}^{0}$ removal mechanism was a rapid gasphase reaction between iodine vapors and $\mathrm{Hg}^{\circ}$, probably yielding mercuric iodide. This gas-phase reaction may explain why a considerable portion $(-35 \%)$ of the total mercury found in the liquid phase was found in bubblers \#2 and \#3. However, as discussed above, we cannot exclude the possibility that some of the mercury found in bubbler \#1 was from a liquid-phase reaction at the gas-liquid interface. Indeed, a published report on the reaction of iodine in solution with dissolved $\mathrm{Hg}^{\mathrm{o}}$ stated that "the rate was too fast to measure." The product of the solution reaction was shown to be mercuric iodide by its ultraviolet spectrum. Therefore, without further modeling studies and knowledge of the rate constants (no experimental data on the gas-phase reaction of $\mathrm{Hg}^{0}$ with iodine could be found in the literature), we cannot specifically analyze how much of each reaction (gas phase versus liquid phase) is responsible for the mercury found in bubbler \#1.

We conclude that the reaction of $\mathrm{Hg}^{0}$ with iodine is extremely rapid in the gas phase. However, the presence of other gases readily interferes with this reaction. Whether this interference is caused only by reaction of iodine with the other gaseous components, or whether another mechanism is responsible for the interference, cannot be determined from these tests. In any case, iodine does not appear to be an attractive option for the oxidation of elemental $\mathrm{Hg}^{0}$ in the presence of gases other than nitrogen.

\section{Bromine Solutions}

A commercial solution containing $3 \%$ bromine (by weight) was used to prepare a solution containing about $250 \mathrm{ppm}$ bromine. This concentration was chosen so that the reagent cost would be approximately equal to that for a $2,500 \mathrm{ppm}$ chlorine solution. This solution was tested with three different gas compositions. Results for those tests are given in Table 2 as percentages of the total inlet mercury found in the liquids from all three bubblers. In other words, we first calculated the total amount of $\mathrm{Hg}^{\circ}$ in the gas phase that entered the bubbler apparatus based on the known rate of $\mathrm{Hg}^{0}$ permeation multiplied by the 30 -min duration of each test. Then, the total mercury in the bubblers was found by adding the amounts found in the individual bubblers (in general, bubbler \#3 was not analyzed for mercury unless a significant amount was found in bubbler \#2). Finally, the total liquid-phase mercury was divided by the total gas-phase mercury, and the result was multiplied by 100 to yield a percentage. As can be seen in Table 2, the highest $\mathrm{Hg}^{\circ}$ removal was obtained in the test without either nitric oxide or sulfur dioxide. 
Adding nitric oxide to the gas mixture resulted in a significant decrease in the $\mathrm{Hg}^{\circ}$ removal, while adding sulfur dioxide resulted in an even larger decrease in the removal performance. This decrease was presumably caused by the consumption of bromine in reactions with the two species, which in the case of dissolved sulfur dioxide would yield bromide and sulfate ions.

\section{Chlorine Solutions}

Solutions of molecular chlorine are more complex than those of iodine because of the greater tendency of chlorine to disproportionate in aqueous solution to hypochlorous acid and chloride ions. Bromine demonstrates intermediate characteristics in this regard. Commercial chlorine solutions are sold as sodium hypochlorite because, in alkaline solutions, the equilibrium between molecular chlorine and hypochlorite ions greatly favors the latter. Nonetheless, because of the various equilibria involved, detectable amounts of chlorine will exist in both the gas and liquid phases. Table 3 presents the results for the removal of $\mathrm{Hg}$ by chlorine solutions, which appear to depend both on the composition of the feedgas mixture and, in some cases, on the concentration of the chlorine solution.

For gas mixtures containing only oxygen and nitrogen, the $\mathrm{Hg}^{0}$ removal did not change appreciably for different chlorine solution concentrations. To help us understand the observed behavior, we surveyed the literature for data on the gas-phase reaction of $\mathrm{Hg}^{\mathbf{0}}$ with chlorine. Recent modeling work has assumed the rate constant to be very small. ${ }^{8}$ However, laboratory experiments have yielded conflicting results. Some workers have found this reaction to be slow, ${ }^{9}$ while others have found it to be relatively fast. ${ }^{10}$ Still other work has shown the reaction of $\mathrm{Hg}^{0}$ with chlorine to be surface catalyzed. ${ }^{11}$ It appears from these conflicting results that one must be very careful in interpreting data for this reaction. Our data suggest that the rate of reaction between $\mathrm{Hg}^{\circ}$ and chlorine is not fast, because not much change in $\mathrm{Hg}^{\circ}$ removal was observed with increasing chlorine concentration. Our conclusion on the gas-phase reaction of $\mathrm{Hg}^{\circ}$ with chlorine is that it is slow unless there is an appropriate surface available to catalyze the reaction.

For the gas mixtures containing nitric oxide or nitric oxide plus sulfur dioxide, $\mathrm{Hg}^{0}$ removal increased with increasing chlorine concentration. However, the rate of increase differed for the two gas mixtures. Addition of nitric oxide to the feed-gas mixture appeared to have a definite positive effect on the amount of mercury transferred to the liquid phase, as compared with the removals obtained with only oxygen and nitrogen present. An explanation for this behavior might be that nitric oxide reacts with chlorine to yield nitrosyl chloride. This reaction has been described in the literature and appears to occur rapidly at room temperature. ${ }^{12}$ Although we could not find a literature reference to the reaction of nitrosyl chloride with $\mathrm{Hg}^{0}$, one paper did report that nitrosyl chloride oxidizes mercurous chloride to mercuric chloride, as well as oxidizing elemental zinc and copper. ${ }^{13}$ Our conclusion for the reaction of $\mathrm{Hg}^{0}$ in the presence of nitric oxide is that nitrosyl chloride probably reacts faster with $\mathrm{Hg}^{0}$ than chlorine does.

The results in Table 3 also show that when sulfur dioxide is added to the feed-gas mixture, $\mathrm{Hg}^{0}$ removal is much lower at the lower chlorine concentrations than when sulfur dioxide is not present. However, at the highest chlorine concentration studied $(5,000 \mathrm{ppm})$, the $\mathrm{Hg}^{\circ}$ removal performance with sulfur dioxide present was actually slightly higher than the performance without sulfur dioxide. It is difficult to postulate a mechanism in which the presence of sulfur dioxide could actually increase the oxidation of $\mathrm{Hg}^{\circ}$ by chlorine, because it is well known that sulfite ions will reduce molecular halogens to their corresponding halides. Perhaps the improvement in $\mathrm{Hg}^{0}$ removal with chlorine concentration can be 
understood as simply the result of an excess of chlorine that swamps the reaction between dissolved bisulfite (from absorbed sulfur dioxide) and chlorine and/or hypochlorite ions in solution.

Figure 2 presents a graph showing the fraction of the inlet mercury that was found in the bubblers as a function of the initial chlorine concentration in bubbler \#1. The data are for the case in which both nitric oxide and sulfur dioxide were present in the feed gas. A power curve of the form $y=a \cdot x^{b}+c$ has been used to fit the data as a guide to showing the dependence of removal on chlorine concentration for this combination of gases. A more complete understanding of the basis for this behavior will require further detailed testing.

\section{Chloric-Acid Solutions}

Chloric-acid solutions were prepared from concentrated NOXSORB ${ }^{\mathrm{TM}}$, which has a nominal composition of $17.8 \%$ chloric acid and $22.3 \%$ sodium chlorate. Tests with three different concentrations were performed: $0.71 \%$ chloric acid ( $25: 1$ dilution of the concentrated stock solution), $1.78 \%$ chloric acid (10:1 dilution), and 3.56\% chloric acid (5:1 dilution). The primary vapor-phase species above these solutions is thought to be chlorine dioxide. However, chlorine dioxide is very reactive and readily photolyzes to molecular chlorine and oxygen. Also, in the presence of moisture, chlorine dioxide can produce a number of different chlorine oxyacids, such as hypochlorous acid and chlorous acid. Therefore, a large number of different species may be present in the vapor above a chloric-acid solution. To the best of our knowledge, there has been no previous research addressing the reaction of $\mathrm{Hg}^{\circ}$ with either chlorine dioxide or chlorate anions.

Results of our tests with different chloric-acid concentrations are shown in Table 4. The change in $\mathrm{Hg}^{\circ}$ removal from a solution of $0.71 \%$ chloric-acid concentration to one with about a five times higher concentration is about the same for each of the three different feed-gas mixtures. In each case, the $\mathrm{Hg}^{\circ}$ removal was about a factor of two higher with the $3.56 \%$ chloric-acid solution. Next, we note that gas mixtures containing nitric oxide showed a substantially higher $\mathrm{Hg}^{0}$ removal than the gas mixtures without nitric oxide. This result is similar to what was observed with chlorine solutions. However, a different chemical mechanism is probably responsible in this case. The reaction of nitric oxide with NOXSORB ${ }^{\mathrm{TM}}$ solutions may produce hydrochloric and nitric acids among its products. ${ }^{14}$ Because nitric acid dissolves liquid elemental mercury, we propose that this gaseous by-product causes the improved $\mathrm{Hg}^{0}$ removal when nitric oxide is present in the gas stream. The results of these tests suggest that the gas-phase reaction of $\mathrm{Hg}^{\circ}$ with nitric acid might be rapid and should be examined further.

Contrary to the behavior observed with chlorine, we found that for both concentrations studied, the presence of sulfur dioxide in the feed-gas stream reduced the $\mathrm{Hg}^{0}$ removal by about $30 \%$ from the level without sulfur dioxide (but with NO). Also in contrast to the behavior observed with chlorine solutions, it appears that within this range of chloric-acid concentrations, the reduction in $\mathrm{Hg}^{0}$ removal when sulfur dioxide is present cannot be overcome with higher chloric-acid concentrations. This result again points to the possibility that a mechanism different from chlorine oxidation of $\mathrm{Hg}^{0}$ is operating for these solutions.

\section{Small-Bubble Tests}

The small-bubble tests were performed to learn more about the relative importance of gas-phase versus liquid-phase mechanisms in the $\mathrm{Hg}^{0}$ removal processes. For a constant volume of gas, the smaller bubbles 
produce a larger gas-liquid contact area, which is proportional to the total gas-bubble surface area. Thus, it was expected that the small-bubble tests might be dominated by gas-liquid interactions, in contrast to the large-bubble tests where gas-gas interactions would be more important.

\section{Bromine Solutions}

Only two bromine tests were performed with the small-bubble apparatus. Both tests used a solution of $250 \mathrm{ppm}$ bromine in bubbler \#1. One test used a feed-gas mixture of oxygen plus nitrogen (plus $\mathrm{Hg}^{\circ}$ ) and gave a $\mathrm{Hg}^{0}$ removal of $53.2 \%$. This test may be compared with a similar large-bubble test that gave a removal of 71.1\%. A second test used a feed-gas mixture of oxygen plus nitrogen plus carbon dioxide plus nitric oxide and gave $\mathbf{~ H g}^{0}$ removal of $28.5 \%$. This test may be compared with similar large-bubble tests that gave a $\mathrm{Hg}^{0}$ removal of $46.8 \%$ (average of two tests). Because the large-bubble tests gave better $\mathrm{Hg}^{0}$ removals in both cases, gas-phase interactions for bromine may be more effective for $\mathrm{Hg}^{0}$ oxidation and subsequent removal than any gas-liquid interactions. Another possibility is that the reactive species for oxidation may be more effectively degraded through reactions involving the gas-liquid interface.

\section{Chlorine Solutions}

Results for the small-bubble tests using chlorine solutions are shown in Table 5. The remarkable result found for these tests is that approximately the same $\mathrm{Hg}^{0}$ removal performance $(16.5 \% \pm 1.9 \%)$ was observed regardless of chlorine concentration (from $100 \mathrm{ppm}$ to $2,500 \mathrm{ppm}$ ) or gas composition. This finding indicates that a single mechanism, most likely involving gas-liquid contact, is dominating $\mathrm{Hg}^{\mathbf{0}}$ removal under these conditions. By comparing the data in Tables 3 and 5, it appears that gas-phase interactions become more important for higher chlorine concentrations ( $>250 \mathrm{ppm}$ ) and for feed gas mixtures containing either nitric oxide alone or nitric oxide plus sulfur dioxide.

\section{Chloric-Acid Solutions}

Table 6 gives results for the small-bubble tests using NOXSORB ${ }^{\mathrm{TM}}$ solutions in bubbler \#1. The pattern for those results is similar to what was obtained in the chlorine tests, with little variation in $\mathrm{Hg}^{0}$ removal $(35.5 \% \pm 6.0 \%)$ regardless of chloric-acid concentration or gas composition. Presumably, this result indicates that a single mechanism was dominating $\mathrm{Hg}^{0}$ removal. By comparing the data in Tables 4 and 6 , it again appears that gas-phase interactions become more important at higher chloric-acid concentrations $(>10 \%)$ and with either nitric oxide alone or nitric oxide plus sulfur dioxide present in the gas stream.

\section{Conclusions}

Previous research at Argonne and elsewhere has indicated that typical wet FGD systems are not effective in controlling emissions of elemental mercury. Although more intensive scrubbing with the addition of certain types of packing may yield some degree of control, a more effective approach could be to convert the mercury into a form that is readily absorbed. Our research thus far has shown that halogen-containing solutions are capable of promoting gaseous, elemental-mercury removal by aqueous solutions, presumably by oxidizing the $\mathrm{Hg}^{0}$ to soluble compounds, such as mercuric chloride. The specific behavior of these solutions depends on many factors, including the reactive species, the gas-phase composition, and the degree to which gas-gas or gas-liquid reactions are important. 
An FGD process modified for mercury control would probably involve upstream injection of a reactive species, with $\mathrm{Hg}^{\circ}$ conversion depending upon gas-phase reactions. Our large-bubble tests emphasize gas-phase interactions and yield several conclusions. Iodine solutions can be effective in oxidizing $\mathrm{Hg}^{\circ}$, even at very low concentrations $(<1 \mathrm{ppm})$. This appears to be due to a rapid gas-phase reaction. However, that effectiveness is lost when species other than nitrogen and $\mathrm{Hg}^{\circ}$ are in the gas stream. For bromine, somewhat higher concentrations $(250 \mathrm{ppm})$ again produced substantial conversion of $\mathrm{Hg}^{0}$, but the addition of nitric oxide and sulfur dioxide diminished that conversion significantly. Thus, neither iodine nor bromine is likely to be cost-effective in a commercial system.

A different pattern of behavior was found for solutions containing chlorine or chlorine compounds. Chlorine solutions showed no dependence on concentration when nitric oxide and sulfur dioxide were absent, indicating that the mercury-chlorine reaction is probably slow without the presence of a catalyst. Addition of nitric oxide to the gas stream greatly increased the amount of $\mathrm{Hg}^{0}$ removed. This increase in removal may have been due to the formation of an intermediate compound, such as nitrosyl chloride, which reacted rapidly with the $\mathbf{H g}^{\mathbf{0}}$. On the other hand, sulfur dioxide depressed the $\mathrm{Hg}^{\mathbf{0}}$ removal, at least at lower concentrations. Nevertheless, the removal appeared to increase with chlorine concentration when either nitric oxide alone or nitric oxide plus sulfur dioxide were added to the gas stream.

Mercury removal with chloric-acid solutions also appeared to increase with increasing chloric-acid concentration regardless of gas composition. In a similar manner to chlorine, the presence of nitric oxide greatly increased $\mathrm{Hg}^{0}$ removal. In this case, the important gas-phase reaction may involve nitric acid formed from the reaction of nitric oxide and chloric acid. The presence of sulfur dioxide decreased $\mathrm{Hg}^{0}$ removal, but it remained intermediate to that with and without nitric oxide.

For the small-bubble tests, gas-liquid interactions should play a larger role. The tests with bromine indicated that gas-phase reactions are probably more effective for $\mathrm{Hg}^{0}$ oxidation than gas-liquid interactons. For both chlorine and chloric-acid solutions, $\mathrm{Hg}^{\circ}$ removal appeared to be constant regardless of solute concentration or gas-phase composition. The average removal with chlorine solutions was about $17 \%$, while the average removal with chloric-acid solutions was about $34 \%$. In comparing these results with those for large bubbles, it appears that (within the range studied) higher concentrations of either chlorine or chloric acid could be effective for gas-phase oxidation of $\mathrm{Hg}^{\mathbf{0}}$, even in the presence of nitric oxide and/or sulfur dioxide. As indicated in the earlier scrubber experiments, some degree of nitricoxide removal may also be obtained as part of the reaction mechanism. Soluble oxidation products could then be removed in a downstream aqueous scrubber system. Further scrubber experiments are being designed to test the potential of this approach for yielding an integrated sulfur dioxide/nitrogen oxides/mercury control process.

\section{Acknowledgments}

This work was supported by the U.S. Department of Energy, Assistant Secretary for Fossil Energy, under contract W-31-109-ENG-38, through the Federal Energy Technology Center (previously the Pittsburgh Energy Technology Center). We gratefully acknowledge the support and guidance provided by Perry Bergman and Tom Brown of the Center. In addition, we extend our appreciation to Sherman Smith of Argonne for his many contributions to our laboratory operations. 


\section{References}

1. Livengood, C.D.; Huang, H.S.; Mendelsohn, M.H.; Wu, J.M., 1996, "Enhancement of Mercury Control in Flue-Gas Cleanup Systems," Proc. U.S. DOE/PETC First Joint Power \& Fuel Systems Contractors Conference, Pittsburgh, Penn., July 9-11.

2. Chang, R.; Hargrove, B.; Carey, T.; Richardson, C.; Meserole, F., 1996, "Power Plant Mercury Control Options and Issues, " Proc. POWER-GEN '96 International Conference, Orlando, Fla., Dec. 4-6.

3. Huang, H.S.; Wu, J.M.; Livengood, C.D., 1995, "Development of Dry Control Technology for Emissions of Mercury in Flue Gas," Proc. The Fourth International Congress on Toxic Combustion Byproducts, Berkeley, Calif. June 5-7.

4. Mendelsohn, M.H.; Wu, J.; Huang, H.; Livengood, C.D., 1994, "Elemental Mercury Removals Observed in a Laboratory-Scale Wet FGD Scrubber System," Emerging Clean Air Technologies and Business Opportunities, Toronto, Canada, Sept. 26-30.

5. Mendelsohn, M.H.; Harkness, J.B.L., 1991, "Enhanced Flue-Gas Denitrification Using Ferrous•EDTA and a Polyphenolic Compound in an Aqueous Scrubber System, "Energy \& Fuels, 5(2):244-247.

6. Livengood, C.D.; Mendelsohn, M.H.; Huang, H.S.; Wu, J.M., 1995, "Development of Mercury Control Techniques for Utility Boilers," 88th Annual Meeting Air \& Waste Management Association, San Antonio, Texas, June 18-23.

7. Warrick, Jr., P.; Wewerka, E.M.; Kreevoy, M.M., 1962, "The Reactions of Iodine in Solution with Elemental Mercury," J. Am. Chem. Soc., 85:1909-1915.

8. Pleijel, K.; Munthe, J., 1995, "Modelling the Atmospheric Mercury Cycle - Chemistry in Fog Droplets," Atmospheric Environment, 29:1441-1457.

9. Skare, I.; Johansson, R., 1992, "Reactions Between Mercury Vapor and Chlorine Gas at Occupational Exposure Levels," Chemosphere, 24:1633-1644.

10. Skripnik, V.A.; Fedorovskaya, L.F.; Kravetskii, L.I.; Umanskaya, I.M., 1979, "Mechanism and Kinetics of Mercury Oxidation by Chlorine-Containing Solutions," Zh. Prikl. Khim. (Leningrad), 52:1233-1237 (Engl. trans. 1169-1172).

11. Medhekar, A.K.; Rokni, M.; Trainor, D.W.; Jacob, J.H., 1979, "Surface Catalyzed Reaction of $\mathrm{Hg}+\mathrm{Cl}_{2}$," Chem. Phys. Letters, 65:600-604.

12. Stoddart, E.M., 1944, "The Kinetics of the Reaction between Chlorine and Nitric Oxide," J. Chem. Soc., 388-393. 
13. Partington, J.R.; Whynes, A.L., 1948, "The Action of Nitrosyl Chloride on Some Metals and Their Compounds," J. Chem. Soc., 1952-1958.

14. Kaczur, J.J., 1996, "Oxidation Chemistry of Chloric Acid in NOx/SOx and Air Toxic Metal Removal from Gas Streams," Environmental Progress, 15(4):245-254.

Table 1. List of selected chemical formulas.

\begin{tabular}{|c|c|}
\hline Chemical Name & Chemical Formula \\
\hline Bromine & $\mathrm{Br}_{2}$ \\
\hline Carbon Dioxide & $\mathrm{CO}_{2}$ \\
\hline Calcium Hydroxide & $\mathrm{Ca}(\mathrm{OH})_{2}$ \\
\hline Chloric Acid & $\mathrm{HClO}_{3}$ \\
\hline Chlorine & $\mathrm{Cl}_{2}$ \\
\hline Chlorous Acid & $\mathrm{HClO}_{2}$ \\
\hline Hypochlorous Acid & $\mathrm{HOCl}$ \\
\hline Iodine & $\mathrm{I}_{2}$ \\
\hline Mercury (elemental) & $\mathbf{H g}^{0}$ \\
\hline Mercuric Chloride & $\mathrm{HgCl}_{2}$ \\
\hline Nitric Oxide & No \\
\hline Nitrogen & $\mathrm{N}_{2}$ \\
\hline Nitrogen Oxides & $\mathrm{NO}_{\mathrm{x}}$ \\
\hline Nitrosyl Chloride & $\mathrm{NOCl}$ \\
\hline Oxygen & $\mathrm{O}_{2}$ \\
\hline Sodium Chlorate & $\mathrm{NaClO}_{3}$ \\
\hline
\end{tabular}

Table 2. Summary of $\mathrm{Hg}^{\mathrm{0}}$ removal results for large-bubble tests with a $250 \mathrm{ppm}$ bromine solution.

\begin{tabular}{lc}
\hline \multicolumn{1}{c}{ Feed-Gas Composition } & $\mathrm{Hg}^{0}$ Removal (\%) \\
\hline $\mathrm{O}_{2}+\mathrm{N}_{2}+\mathrm{Hg}^{0}$ & 71.1 \\
$\mathrm{O}_{2}+\mathrm{N}_{2}+\mathrm{NO}+\mathrm{CO}_{2}+\mathrm{Hg}^{0}$ & $50.9,42.6$ \\
$\mathrm{O}_{2}+\mathrm{N}_{2}+\mathrm{NO}+\mathrm{CO}_{2}+\mathrm{SO}_{2}+\mathrm{Hg}^{0}$ & 11.8 \\
\hline
\end{tabular}


Table 3. Summary of $\mathrm{Hg}^{\mathbf{0}}$ removal results for large-bubble tests with chlorine solutions.

\begin{tabular}{l|ccccc}
\hline \multirow{2}{*}{\multicolumn{1}{c|}{ Feed-Gas Composition }} & \multicolumn{5}{|c}{ Chlorine Concentration (ppm) } \\
\cline { 2 - 6 } & 2.5 & 250 & 1,000 & 2,500 & 5,000 \\
\cline { 2 - 6 } & \multicolumn{5}{c}{$\mathrm{Hg}^{0}$ removal (\%) } \\
\hline $\mathrm{O}_{2}+\mathrm{N}_{2}+\mathrm{Hg}^{0}$ & 11.6 & $14.4,13.3$ & $-\ldots$ & 9.3 & 14.3 \\
$\mathrm{O}_{2}+\mathrm{N}_{2}+\mathrm{NO}+\mathrm{CO}_{2}+\mathrm{Hg}^{0}$ & 19.0 & $45.2,41.8$ & $35.4,28.1$ & 27.5 & 44.5 \\
$\mathrm{O}_{2}+\mathrm{N}_{2}+\mathrm{NO}+\mathrm{CO}_{2}+\mathrm{SO}_{2}+\mathrm{Hg}^{0}$ & 0.5 & 13.8 & 25.6 & $35.4,31.0$ & 52.2 \\
\hline
\end{tabular}

Table 4. Summary of $\mathrm{Hg}^{0}$ removal results for large-bubble tests with $\mathrm{HClO}_{3}$ solutions.

\begin{tabular}{l|ccc}
\hline \multirow{2}{*}{\multicolumn{1}{c|}{ Feed-Gas Composition }} & \multicolumn{3}{|c}{$\mathrm{HClO}_{3}$ Concentration (\%) } \\
\cline { 2 - 4 } & 0.71 & \multicolumn{3}{c}{1.78} & 3.56 \\
\cline { 2 - 4 } $\mathrm{Hg}^{0}$ removal (\%) \\
\hline $\mathrm{O}_{2}+\mathrm{N}_{2}+\mathrm{Hg}^{0}$ & 14.0 & --- & 26.9 \\
$\mathrm{O}_{2}+\mathrm{N}_{2}+\mathrm{NO}+\mathrm{CO}_{2}+\mathrm{Hg}^{0}$ & 33.9 & --- & 69.6 \\
$\mathrm{O}_{2}+\mathrm{N}_{2}+\mathrm{NO}+\mathrm{CO}_{2}+\mathrm{SO}_{2}+\mathrm{Hg}^{0}$ & 22.8 & 17.1 & 48.2 \\
\hline \hline
\end{tabular}

Table 5. Summary of $\mathrm{Hg}^{0}$ removal results for small-bubble tests with chlorine solutions.

\begin{tabular}{|c|c|c|c|c|}
\hline \multirow[b]{3}{*}{ Feed-Gas Composition } & \multicolumn{4}{|c|}{ Chlorine Concentration (ppm) } \\
\hline & 100 & 250 & 500 & 2,500 \\
\hline & \multicolumn{4}{|c|}{$\mathrm{Hg}^{0}$ removal (\%) } \\
\hline $\mathrm{O}_{2}+\mathrm{N}_{2}+\mathrm{Hg}^{\mathrm{o}}$ & ---- & 17.1 & ---- & 16.7 \\
\hline $\mathrm{O}_{2}+\mathrm{N}_{2}+\mathrm{NO}+\mathrm{CO}_{2}+\mathrm{Hg}^{\mathrm{o}}$ & 17.5 & 15.0 & 16.4 & 15.0 \\
\hline $\mathrm{O}_{2}+\mathrm{N}_{2}+\mathrm{NO}+\mathrm{CO}_{2}+\mathrm{SO}_{2}+\mathrm{Hg}^{0}$ & 13.9 & --- & $-\cdots$ & 20.0 \\
\hline
\end{tabular}


Table 6. Summary of $\mathrm{Hg}^{0}$ removal results for small-bubble tests with $\mathrm{HClO}_{3}$ solutions.

\begin{tabular}{l|cccc}
\hline \multirow{2}{*}{\multicolumn{1}{c|}{ Feed-Gas Composition }} & \multicolumn{4}{|c}{$\mathrm{HClO}_{3}$ Concentration (\%) } \\
\cline { 2 - 5 } & 0.356 & \multicolumn{4}{c}{0.71} & 1.78 & 3.56 \\
\cline { 2 - 5 } $\mathrm{O}_{2}+\mathrm{N}_{2}+\mathrm{Hg}^{\circ}$ & - & \multicolumn{4}{c}{ removal (\%) } \\
$\mathrm{O}_{2}+\mathrm{N}_{2}+\mathrm{NO}+\mathrm{CO}_{2}+\mathrm{Hg}^{\circ}$ &.-- & $34.6,28.4$ & $\cdots$ & 40.8 \\
$\mathrm{O}_{2}+\mathrm{N}_{2}+\mathrm{NO}+\mathrm{CO}_{2}+\mathrm{SO}_{2}+\mathrm{Hg}^{\circ}$ & 28.9 & 39.9 & 35.4 & 38.7 \\
\hline
\end{tabular}

Figure 1. Removals of $\mathrm{Hg}^{0}, \mathrm{NO}$, and $\mathrm{SO}_{2}$, in a wet scrubber with a $4 \%$ NOXSORB ${ }^{\mathrm{TM}}$ solution.

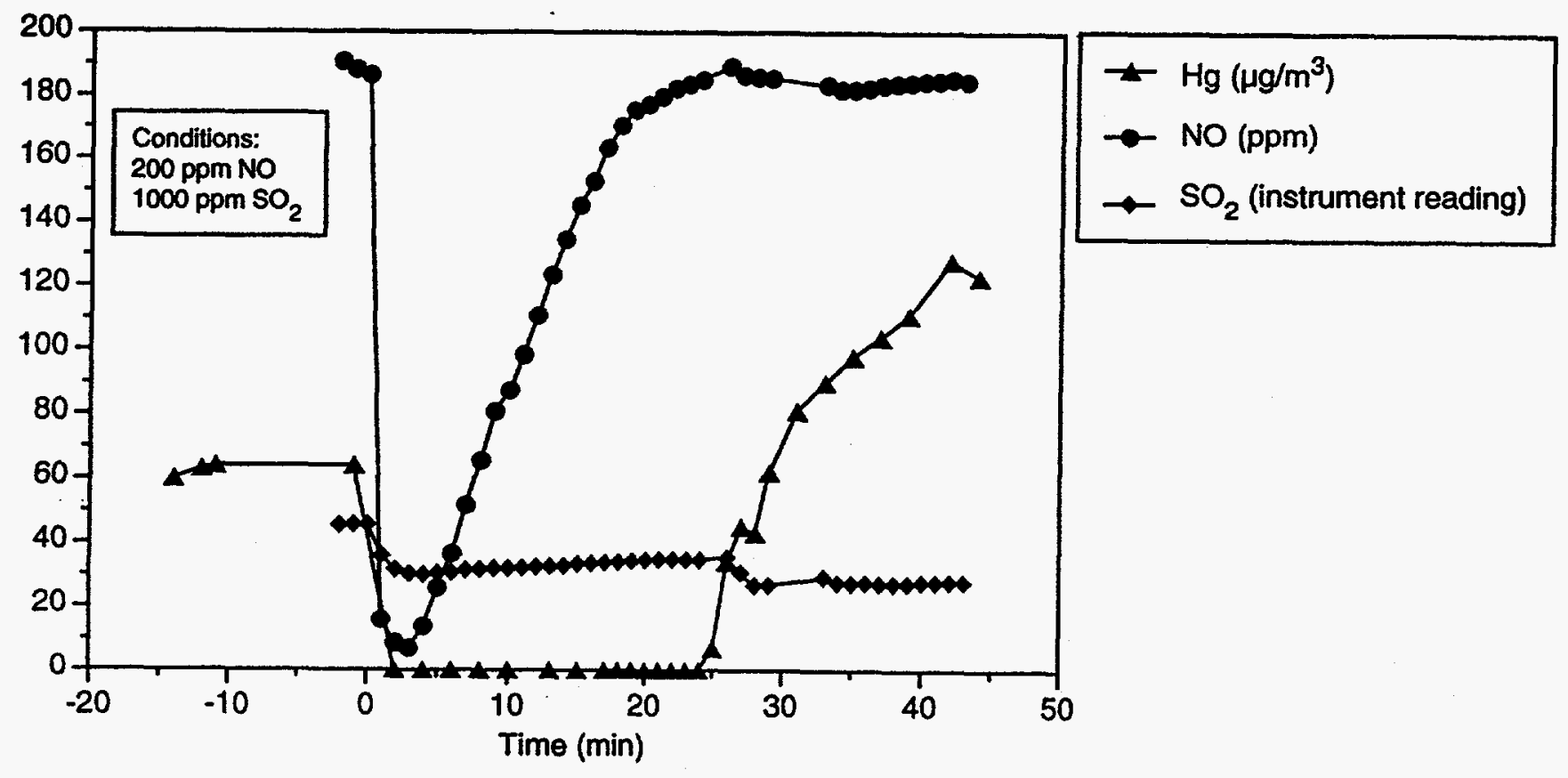


Figure 2. Dependence of $\mathrm{Hg}^{0}$ removal on the chlorine concentration for a gas mixture containing NO
and $\mathrm{SO}_{2}$.

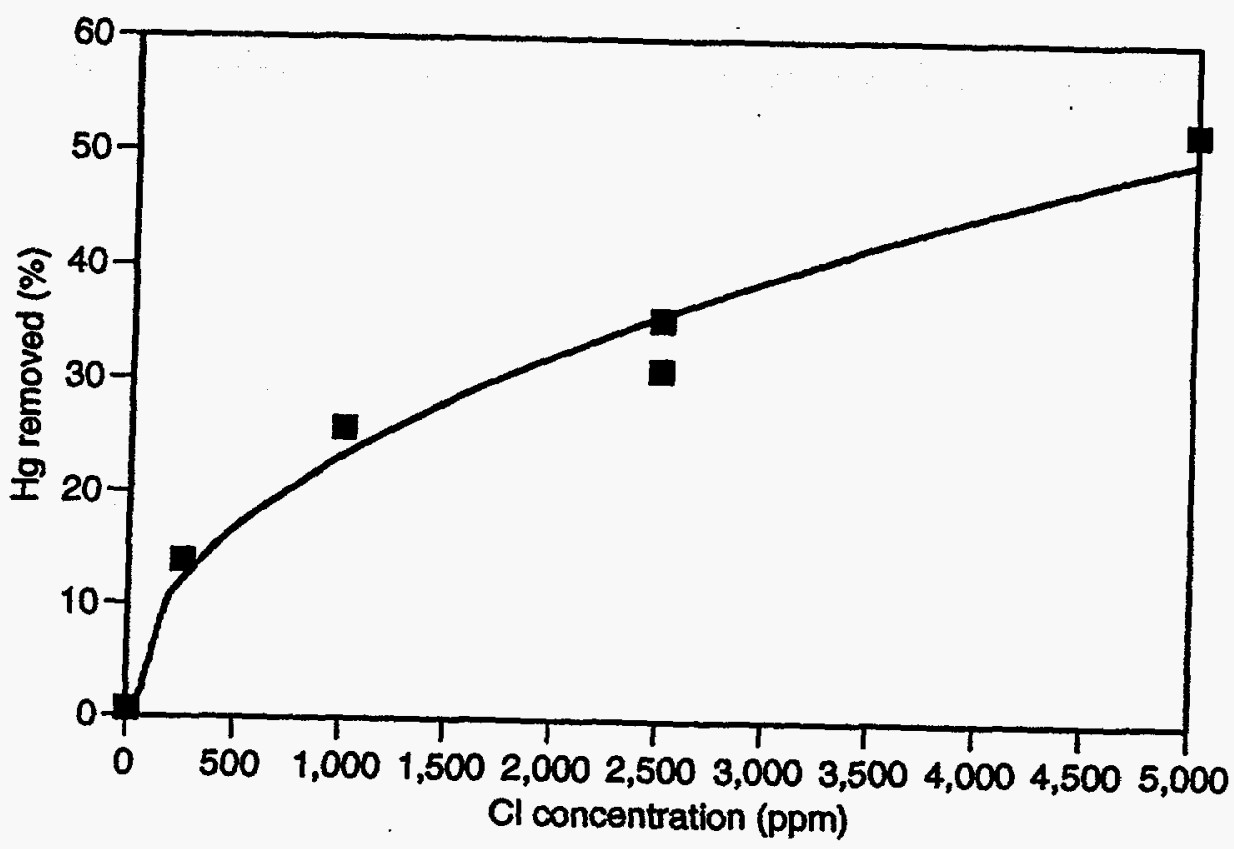

\section{DISCLAIMER}

This report was prepared as an account of work sponsored by an agency of the United States Government. Neither the United States Government nor any agency thereof, nor any of their empicyees, makes any warranty, express or implied, or assumes any legal liability or responsibility for the accuracy, completeness, or usefulness of any information, apparatus, product, or process disclosed, or represents that its use would not infringe privately owned rights. Reference herein to any specific commercial product, process, or service by trade name, trademark, manufacturer, or otherwise does not necessarily constitute or imply its endorsement, recom: mendation, or favoring by the United States Government or any agency thereof. The views and opinions of authors expressed herein do not necessarily state or reflect those of the United States Government or any agency thereof. 